\title{
EDUCACIÓN DE CALIDAD \\ Y DESEMPEÑO DOCENTE ${ }^{1}$
}

\section{QUALITY EDUCATION \\ AND TEACHERS' PERFORMANCE}

Dr. Mario Sandoval $\mathrm{M}^{2}$

Chile.

Palabras Clave: Educación, calidad, desempeño docente

Keywords: Education, quality, teacher`s performance

\section{RESUMEN}

Los intentos de mejorar la calidad de la educación en Chile se caracterizan por la voluntad de todos los involucrados en el sistema educativo, en generar mecanismos que permitan llevar a cabo estrategias que, efectivamente, ofrezcan reales oportunidades de mejoramiento y equidad. En este sentido, se destaca el histórico acuerdo tripartito entre Ministerio de Educación, Asociación de Municipalidades y Colegio de Profesores, por buscar la manera de mejorar el desempeño del profesorado, mediante la Evaluación de Desempeño Docente. Con ello, se diseña e implementa un sistema de Planes de Superación Profesional a partir de los deficientes resultados de dicha evaluación.

\section{ABSTRACT}

This paper aims at presenting the attempts to improve quality education in Chile characterized by the willingness of involved participants in the
1.Traducción. Carlos A. Muñoz T.

Revisión: Centro de Traducción del Instituto de Idiomas UAM

2. Profesor investigador de la Universidad Católica Silva Henríquez - Chile. PhD en Sociología

El presente artículo forma parte del proyecto FONDECYT No 080218

"Gestión del conocimiento y reforma del pensamiento en educación: reformulaciones epistemológicas y sociopolíticas para programas de formación de profesores y políticas públicas".

Fecha de recibido: Enero 2008

Fecha de aprobación: Agosto 2008

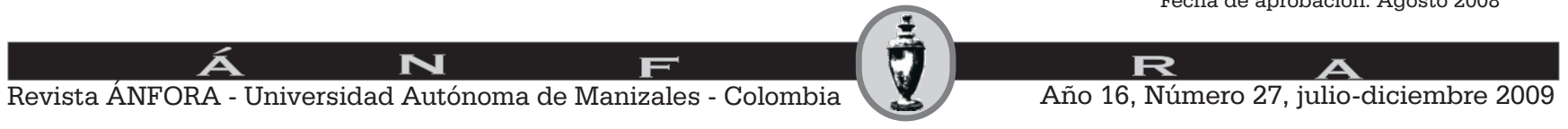


educational system. All participants agree to create mechanisms which permit to carry out effective strategies to offer real opportunities of improvement and equity. In this sense, it is necessary to highlight the historical agreement among the Ministry of Education, the Association of Municipalities and the Teachers' Association about the Assessment of Teachers' Performance. The objective of this assessment is to improve Teachers' Performance by means of designing and implementing a system of Professional Development Plans based on deficient results found in the assessment itself.

\section{INTRODUCCIÓN:}

La investigación en curso: "Gestión del conocimiento y reforma del pensamiento en educación. Reformulaciones epistemológicas y sociopolíticas para programas de formación de profesores" está orientada a comprender fenomenológicamente la experiencia de sentido y aproximación al conocimiento disciplinar y pedagógico de profesores con excelencia pedagógica en el sistema escolar, de los profesores encargados de la formación inicial docente y de estudiantes en formación pedagógica, en consecuencia es de vital interés conocer la evaluación de desempeño docente, como los planes de superación profesional.

\section{Educación de calidad}

Desde la década de los noventa las reformas educativas de varios países de América Latina se propusieron, a partir de acuerdos y recomendaciones de carácter internacional, modernizar la educación. Para ello se planteó el establecimiento de nuevos parámetros curriculares y enfatizar en los principios de calidad y equidad de la educación. Esto implicaría la instrumentación de instancias de evaluación de desempeño docente, de perfeccionamiento, fortalecimiento de la gestión educativa además de la construcción de sistemas de información y evaluación educativa para facilitar la toma de decisiones en materia de políticas educativas. De esta manera, durante la década pasada varios países en América Latina invirtieron en recursos humanos y materiales en importantes transformaciones curriculares. Entre las reformas más significativas pueden mencionarse las de Argentina, Brasil, Chile, Costa Rica, El salvador, Nicaragua, Uruguay. (Vaillant 2005)

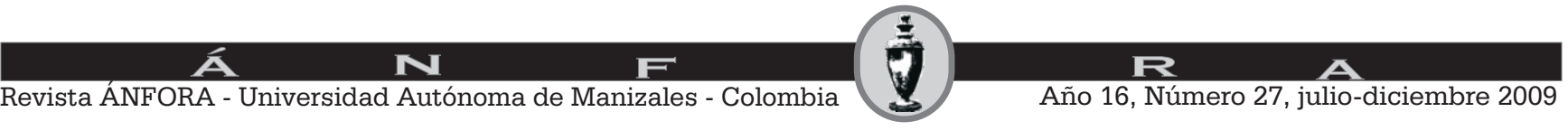


En América Latina, la mayoría de los programas de mejoramiento de la calidad y equidad de los niveles de enseñanza básica y media incluyeron, entre otros, establecimiento de incentivos para la implementación de políticas de estabilidad laboral de los docentes y la capacitación y perfeccionamiento de los profesores en servicio. Aunque podría llegar a afirmarse que "...muchos de estos países han logrado situarse en un nuevo punto de partida, respecto a la mejora de la calidad y equidad en educación, la bondad y pertinencia de estos objetivos, en gran parte, siguen siendo propósitos y todavía no constituyen plenamente una solución, dado que los esfuerzos realizados no han servido del todo, para garantizar un desarrollo educativo sostenido" (Vaillant, 2005). En la práctica, las realidades educativas han demostrado ser difíciles de transformar.

En tal sentido, tanto la experiencia como la investigación han confirmado que uno de los factores claves para conseguir una educación de calidad es contar con docentes de calidad. Desde esa perspectiva, una de las prioridades de los sistemas educativos ha de ser el mantener e incrementar la calidad de sus docentes. (UNESCO 2007)

Es así como una de las actuales preocupaciones de los sistemas educativos tanto de América Latina como de Europa, es la de desarrollar sistemas de carrera docente y de evaluación de desempeño docente que contribuyan al desarrollo profesional y con ello al aumento de la calidad de la enseñanza. Sin embargo, se advierte mediante un estudio (UNESCO, 2007) que hay diferencias y analogías en la carrera y la Evaluación de Desempeño Docente entre los diversos sistemas educativos. No obstante, razones tales como la tradición educativa de un país y necesidades educativas prioritarias marcan las diferencias en este sentido.

Pues bien, situados en la realidad Chilena, en el contexto de la Reforma Educacional se han hecho grandes esfuerzos por elevar la calidad de la educación dado que de acuerdo a los resultados obtenidos, los estándares han sido considerados deficientes. Esta voluntad por mejorar la calidad se dilucidan, por una parte, mediante una serie de acciones tales como mejorías en los programas de estudio. Por su parte, las editoriales también han hecho importantes modificaciones a los textos escolares, por otro lado se han construido Escuelas cada vez con mejores instalaciones, se han incorporado nuevas tecnologías, pero no hay duda que no ha sido suficiente, ya que no es

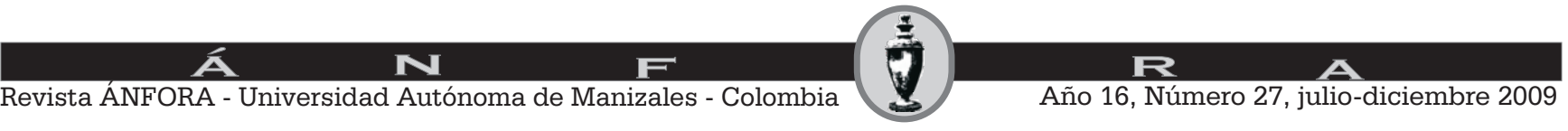


posible sustraerse de la premisa que sin docentes eficientes no será posible obtener mejores resultados en la educación.

Además de considerar la relevancia de las políticas a nivel macro, centralizando la gestión en niveles intermedios, no es posible sustraerse de la realidad que nos señala que el funcionamiento pedagógico se desarrolla a nivel micro, es decir, convergen en las aulas, es ahí donde se aplican las políticas educativas dirigidas a mejorar la calidad de la educación. Tanto los profesores como los directivos de cada establecimiento son parte decisiva al momento de buscar soluciones para intentar mejorar la calidad de la educación, se pretende la transformación educativa por lo que los modelos de evaluación docente están orientados en parte, a la eficacia y al mejoramiento continuo. Por ello es necesario crear una imagen constructiva de la evaluación, difundiendo el planteamiento que ella está a favor del profesor y de su actuación profesional, con la convicción que la calidad se consigue con los docentes y no contra ellos mediante sistemas represivos.

Bastante se habla de mejorar la calidad de la educación, sin embargo al intentar definir qué se entiende por mejorar la calidad de la educación, es posible que en este intento y en el afán por comprender el concepto de calidad, se encuentre una amplia variedad de acepciones, cada una de las cuales es importante considerar. No obstante, una de las formas que se entenderá, educación de calidad será como eficacia, es decir que se dirija a que los alumnos aprendan lo que se supone deben aprender al cabo de determinados ciclos o niveles. Esto es, encarada desde los resultados de aprendizaje efectivamente alcanzados por la acción educativa y por ende por las acciones remediales de los profesores propuestas a partir de los resultados de las evaluaciones, entre ellas de la Evaluación de Desempeño Docente, lo que se conecta necesariamente con el concepto de calidad como mejora continua dadas las propuestas como acciones posteriores a dicha evaluación. Cabe señalar, que no se desconocen otras dimensiones de gran preeminencia que dan cuenta de una educación de calidad como la relevancia y la calidad de los procesos entre otros factores.

Sin duda que para lograr modificar la manera de hacer las cosas y mejorar la calidad, será necesario que las políticas públicas en educación pongan firmemente el acento en la profesionalización docente desde una perspectiva integral (Tenti Fanfani 1995). Esto quiere decir que deben contemplarse, las

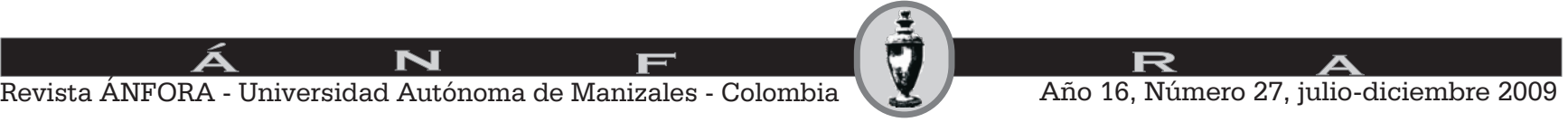


condiciones laborales de los docentes, la formación inicial y el servicio de la gestión institucional. Esto último implica considerar en este proceso a cada uno de los actores que de alguna manera se relacionan con esta temática. Desde el nivel central es decir, desde el MINEDUC, pasando por los Municipios y Corporaciones, hasta llegar a los equipos de gestión de los establecimientos educacionales y por supuesto a los Docentes.

Se admite que se han hecho muchas propuestas para mejorar la calidad de la educación, como ya se ha mencionado entre otras, centrar la atención en la calidad del desempeño docente. En Chile, se pueden señalar algunas acciones llevadas a cabo y que dicen relación con la labor del profesorado, tales como la creación de la Ley de Estatuto Docente, asignación de premios de excelencia, con el objeto de dar estabilidad y profesionalización docente, incluso entrega de premios no monetarios para estimular la docencia con la creación de un fondo especial para perfeccionar profesores dentro y fuera del país.

En este proceso de mejoramiento de desempeño docente en Chile, en que participa tan directamente el profesorado, la idea es que aunando los esfuerzos se logre aprovechar de la mejor manera posible los Planes de Superación Profesional, el cual se implementó a partir de los resultados obtenidos en la Evaluación de Desempeño Docente para los profesores evaluados deficientemente. Lo esperable es que éste considere las necesidades particulares y su contexto específico y que comprometa no sólo a los Municipios o Corporaciones sino que además, a los equipos directivos de las escuelas en el diseño, puesta en marcha y acompañamiento en dicho Plan, puesto que los equipos directivos tienen un alto grado de injerencia en las decisiones y actividades que se llevan a cabo a nivel de aula.

En el marco de la Evaluación de Desempeño Docente, los profesores evaluados reciben la información fundada en las evidencias de sus fortalezas y debilidades respecto a su desempeño. Por su parte, estos resultados les son entregados a los Directores de las Escuelas. Sin embargo, la gestión de los Programas de Superación Profesional queda bajo la responsabilidad de los Encargados Comunales (Municipio o Corporación). A partir de estos resultados se toman decisiones a Nivel Comunal respecto a cómo mejorar, para lo cual se diseñan dichos Planes de Superación Profesional a través de los Encargados Comunales en el mayor de los casos, siendo una de las debilidades del sistema

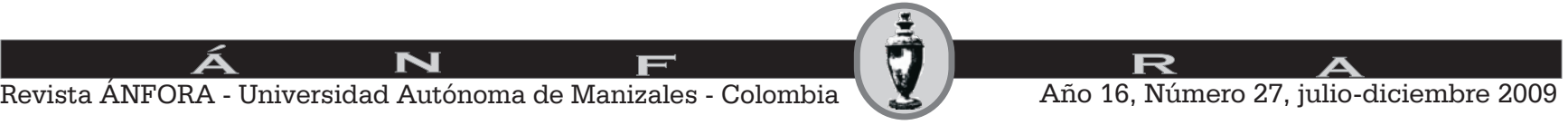


precisamente la falta de valoración de la importancia que tiene considerar los resultados locales de cada Escuela para darle efectividad a la evaluación hecha. Lo esperable, es que se tomen decisiones que conlleven a acciones concretas relacionadas con la superación de la labor docente a partir de los distintos aportes que se pueden recibir de los Directores y Jefes Técnicos para incorporar finalmente al interior de cada establecimiento educacional un proceso de reflexión continua, permanente y de un alto grado de participación de cada uno de los profesionales que están involucrados directamente en él. (Imbernón, 1996)

Más allá de establecer normas para realizar la Evaluación Docente, se hace necesario adoptar el mejor sistema posible que permita llevar a cabo de manera óptima la comunicación de los resultados, y el diseño e implementación de los Planes de Superación Profesional para el mejoramiento del desempeño docente en cada establecimiento educacional, sin desmedro de las actividades que se realizan a nivel comunal. Este planteamiento permitiría que además de las acciones llevadas a cabo por entidades ejecutoras con capacitaciones masivas, los equipos de gestión de las escuelas tuviesen la posibilidad de intervenir directamente en cada establecimiento, con una participación activa promoviendo el perfeccionamiento acorde a las necesidades locales de sus docentes y llevando a cabo un monitoreo cercano y efectivo de dichas capacitaciones .

Los cambios comprometen a todos, Estado, Sostenedores, Escuelas, Docentes, como también a los modelos de pensamiento y de hacer políticas educativas en el país. Se requiere de un cambio de actitud general, para que los docentes dejen de ser considerados como un problema, sino que sean vistos como parte de la solución. Esto ocurrirá sólo si se les reconoce como actores que juegan un papel central para responder a las cuestiones que han quedado pendientes y que son desafíos actualmente. No cabe duda que transformar una educación para que sea de calidad son tareas sociales que involucran a toda la sociedad. Cada una de las instancias que de una u otra forma están vinculadas al acrecentamiento de la calidad de la educación, es decisiva a la hora de buscar soluciones. De no ser así cualquier intento por mejorar será insuficiente.

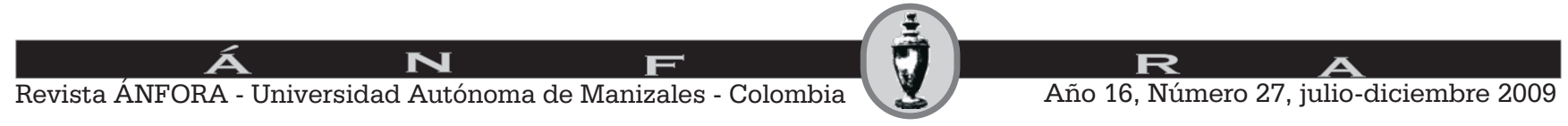




\subsection{Concepto de calidad en el mundo y en Chile}

Cercano al pensamiento estratégico, emerge la visión de calidad total. Con el éxito de Japón en el contexto de la economía mundial, la atención se tornó hacia ese lado. Es conocido el hecho que entre los principales teóricos que inspiraron el cambio en la organización del trabajo en Japón, se encuentran los americanos E. Deming y J. Jurán, quienes en la década del cincuenta, propusieron la filosofía de la calidad en la organización del trabajo. Sin embargo, es sólo mucho más tarde, a mediados de la década de los ochenta, que la preocupación por la calidad se traslada al sistema educativo en USA, evento que ocurre recién a inicio de los años noventa en América Latina (Casassus, 2002).

Sus componentes centrales son por una parte, la identificación de los usuarios y de sus necesidades, el diseño de normas y estándares de calidad, el diseño de procesos que conduzcan hacia la calidad, al mejoramiento continuo de las distintas partes del proceso y la reducción de los márgenes de error que hacen más caros los procesos. Por otra parte, se tiene la preocupación de generar los compromisos de calidad. (Guerra, M. 2007)

En la última década la calidad se ha convertido en un concepto citado por las principales instituciones públicas y de servicios, se ha convertido en una meta que es buscada de una manera completa, ya que se ha considerado de forma común que lo que tiene "calidad" cumple con las expectativas del cliente, la calidad en general abarca todas las cualidades con las que cuenta un producto o un servicio, cuando sus características, tangibles e intangibles satisfacen las necesidades del usuario (Cantú, 2001)

Con la introducción del tema de la calidad en la educación, surgen dos hechos de importancia: por una parte se reconoce la existencia de un "usuario" más allá de las necesidades del aparato del Estado, y por otra parte, se genera la preocupación por el resultado del proceso educativo. Es decir, un proceso en el cual se reconoce el derecho de los diversos usuarios del sistema educativo, a exigir un servicio de calidad de acuerdo a sus necesidades. Como parte de los mecanismos de gestión aparece entonces, la necesidad de hacer visible el resultado del proceso educativo para que los usuarios puedan ver y emitir juicios acerca de la calidad. Por ello, se generaliza el desarrollo de sistemas de medición y evaluación de la calidad de la educación. Pero la preocupación por

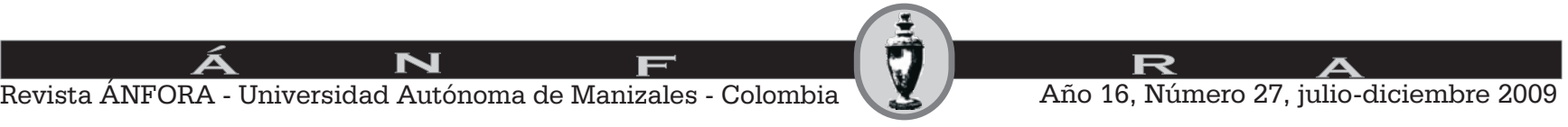


los resultados, y en general por la percepción de un bajo resultado, lleva a analizar y examinar los procesos, los factores y combinación de factores que en ellos intervienen, esto para orientar las políticas educativas en consecuencia.(Casassus. J, 2002)

La visión de la calidad total, es a la vez una preocupación por el resultado y por los procesos. Sin embargo, aún cuando se valora más que nunca el tema educativo, el contenido o significado de calidad en educación queda, en cierta manera, como un supuesto de carácter indefinido. Por lo tanto, el juicio del usuario acerca de la calidad de la educación no se formula sobre un contenido explícito, sino sobre un juicio proyectado por el usuario hacia sus propias concepciones de calidad. Estas concepciones, pueden tener que ver con la calidad de los aprendizajes, pero también puede que no tengan que ver con los aprendizajes u otro fin pedagógico, como lo es el establecimiento de redes sociales. Independiente del objeto sobre el cual el usuario formula el juicio, la sola emergencia de este juicio del usuario, hace que la mirada se vuelva rápidamente hacia los procesos que llevan al producto o servicio que se presta al usuario.

Joseph Juran, considerado un conocedor experto del concepto de calidad, sus mayores aportes se centran entre 1960 y 1990, afirma que cualquier actividad de gestión consiste en tres procesos interrelacionados. Estos son: planificación-control-mejora. Estos tres procesos aplicados a la gestión de calidad, constituyen la denominada trilogía Juran. En otras palabras, se hace referencia a Planificar la calidad, controlar la calidad y mejorarla.

\section{2- Calidad en Chile}

En Chile a fines del Siglo XX, el gobierno de transición a la democracia fijó como norte de sus políticas el logro de una calidad considerablemente más alta y equidad de la provisión de educación financiada públicamente. Con ello redefinió el papel del Estado en el sector, de un papel subsidiario a un papel promotor y responsable de los objetivos de calidad. Esto se tradujo en la presentación de dos criterios articuladores del conjunto de las políticas de los años '90. Por una parte, Programas Integrales de intervención de cobertura universal para el mejoramiento de la calidad de los aprendizajes y por otra, Programas Compensatorios focalizados en las Escuelas y Liceos de menores

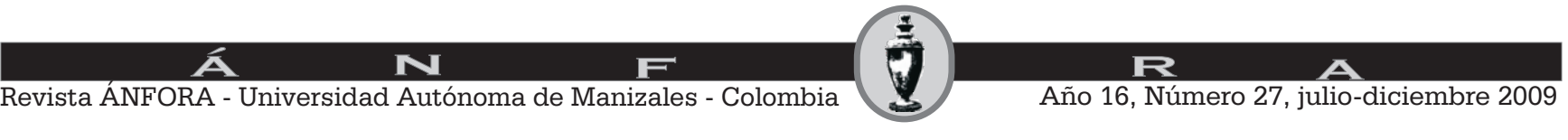


recursos con bajos resultados de aprendizajes para el mejoramiento de la equidad. (PREAL 2003)

El Programa se abordó desde los siguientes ámbitos:

1) Las condiciones políticas, económicas que definen el marco de funcionamiento del sistema escolar en el periodo.

2) Programas de mejoramiento y renovación pedagógica ( a lo largo de una década) tales como:

- Programa de las 900 escuelas

- Programa MECE Básica(1992-1997)

- Programa MECE Media (1995-2000)

- Pasantías y Diplomados de profesores en el extranjero (1996)

- Proyecto Montegrande, masificación Enlaces, Fortalecimiento Docente, Programa de formación inicial, Capacitación reforma curricular (1997)

- Estrategia focalizada para aumentar la retención en Ed. Media ( Liceo para todos) (2000).

- Campaña para la Lectura, Escritura y Matemática de Kª $4^{\circ}$ Básico (2002).

Cabe señalar, que el ámbito cubre diez programas generados e implementados a lo largo de la década, los cuales se traducen en dos programas integrales de cobertura universal, que combinan inversiones en insumos materiales con intervenciones destinadas a la creación o fortalecimiento de capacidades y procesos, cuatro programas de cobertura focalizada en Escuelas y Liceos carenciados, tres programas con focos en docentes y un programa para la implantación de la informática educativa en todo el sistema escolar. (Mineduc.cl)

Con lo anteriormente mencionado, queda de manifiesto que la preocupación por la calidad de la educación, ya no es únicamente un discurso pedagógico, el concepto ha ido orientándose a procurar elementos más operativos que permitan utilizarlo para identificar aspectos relevantes desde el punto de vista de la marcha de los sistemas educativos.

Ha de entenderse además, el concepto de calidad asociado al desarrollo humano y orientado a las virtudes que son necesarias para la vida democrática

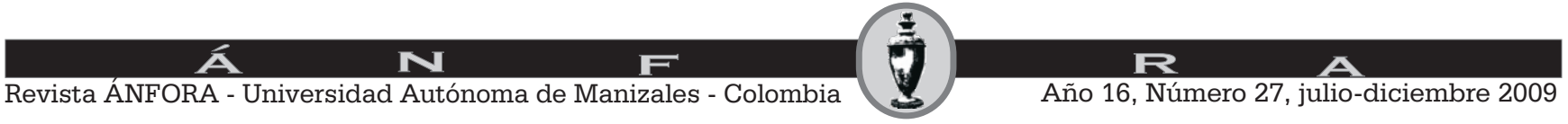


y la integración social. En este sentido, es posible afirmar que se reconoce una dimensión política ideológica del concepto de calidad que se refiere a aquellos aspectos que se vinculan con la definición de los lineamientos generales de la política y una dimensión técnico pedagógica educativa, que se refiere a aquellos aspectos vinculados directamente con la operación, con el quehacer y la gestión pedagógica directamente.

Hablar del mejoramiento continuo es hablar de calidad; y hablar de calidad es hablar de ciencia, educación y paradigmas. La calidad no será nunca el resultado de la improvisación, sino que se obtendrá como consecuencia de planificar los objetivos que se desean alcanzar.

Finalmente cabe señalar, que la educación debe, desde la perspectiva de calidad educativa, garantizar las oportunidades para que cada persona desarrolle al máximo posible sus capacidades cognitivas, emocionales y creativas; aprenda los conocimientos y competencias que le permitan integrarse adecuadamente a la sociedad.

El artículo $4^{\circ}$ de la Declaración Mundial sobre Educación para Todos, titulado "Concentrar la atención en el aprendizaje" señala: "Que el incremento de las posibilidades de educación se traduzca en un desarrollo genuino del individuo y de la sociedad, depende en definitiva, de que los individuos aprendan verdaderamente como resultado de esas posibilidades, esto es, de que verdaderamente adquieran conocimientos útiles, capacidad de raciocinio, aptitudes y valores. En consecuencia, la educación básica debe centrarse en las adquisiciones y los resultados efectivos del aprendizaje, en vez de prestar exclusivamente atención al hecho de matricularse, de participar de forma continuada en los programas de instrucción y de obtener el certificado final. De ahí que sea necesario determinar niveles aceptables de adquisición de conocimientos mediante el aprendizaje en los planes de educación y aplicar sistemas mejorados de evaluación de los resultados" (UNESCO, 1990).

Entre los múltiples y variantes significados al concepto de calidad cabe señalar el criterio de calidad como eficacia, entendida como el logro de los objetivos propuestos por el propio sistema educativo, hoy la preocupación está centrada en el diseño de las estrategias que articulen los elementos externos e internos del sistema escolar con la finalidad de crear más y mejores oportunidades de

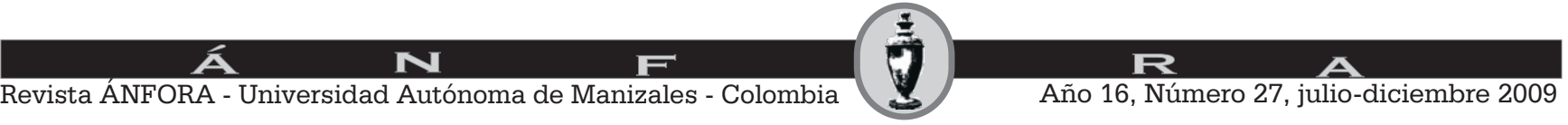


aprendizaje atendiendo a la diversidad de la población. (Seibold, 2000) Si se considera la calidad como la meta del proceso en la educación, éste debe contemplar a cada uno de los elementos que lo integran.

Entonces resulta necesario idear un conjunto de políticas dirigidas, a la vez, a posibilitar y exigir que sean los propios centros de enseñanza y quienes en ellos se desempeñan, los responsables de crear, a partir de su propia experiencia y práctica cotidianas, algunos proyectos de cambio y mejoramiento de la calidad de la enseñanza. En este mismo escenario, es necesario hacer de las Escuelas instituciones más responsables de su propio funcionamiento y de los resultados de su desempeño institucional.

En un contexto de baja calidad educacional, los sistemas de Evaluación Docente se convierten en una de las bases para lograr entender por qué los alumnos no mejoran su rendimiento, y de este modo realizar con la colaboración de todos los agentes implicados, las correcciones correspondientes y asegurar el mejoramiento de la calidad del desempeño docente y por ende de la educación. Entre los múltiples factores que afectan el aprendizaje de los estudiantes, el efecto de los profesores tiene gran importancia.

\section{Antecedentes de Evaluación Docente en América Latina y Europa}

En los últimos años se ha extendido el desarrollo del sistema de Evaluación del Desempeño Docente, fundamentalmente en América Latina, como instrumento para impulsar una mejora de la calidad de la docencia. Un estudio comparado realizado entre 50 países de Europa y América Latina (UNESCO 2007), muestra que muchos países optan preferentemente por sistemas de autoevaluación, ligados frecuentemente a procesos de evaluación interna en cada escuela, siendo ésta una estrategia muy eficaz para lograr un buen desempeño docente centrado en mecanismos de confianza hacia este grupo de profesionales. (UNESCO, 2007)

Para que una propuesta de evaluación docente sea de calidad, ha de tener explicitado el modelo de docente ideal que defiende y en este sentido pocos países han logrado tal definición. Por otra parte, el docente desarrolla su tarea en una organización, es decir en una Escuela, por lo que no es posible evaluar al profesorado sin tener en cuenta los valores de la institución y conocimiento del contexto.

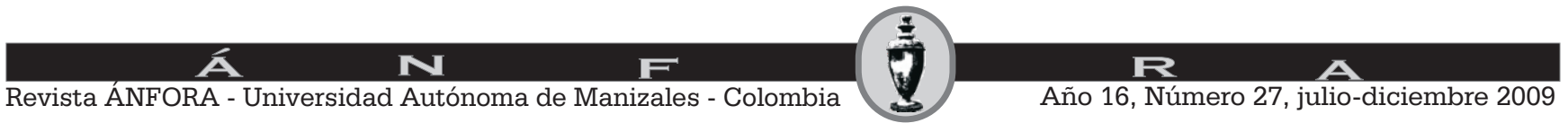


Poco a poco se ha ido extendiendo la importancia de la evaluación del profesorado como medio para su desarrollo profesional. Actualmente el objetivo primordial es ayudar al docente a mejorar su desempeño, identificando sus logros y detectando sus problemas. Según el estudio llevado a cabo por la UNESCO, la evaluación docente externa se da en la mitad de los países analizados y la mayor concentración recae en los países de América Latina y de Europa del Este y en la minoría de Europa Occidental. (UNESCO, 2007)

El estudio de la UNESCO señala que todos los sistemas de Evaluación de Desempeño Docente tienen dos propósitos elementales: 1) Mejorar o asegurar la calidad de la enseñanza, es decir, busca colaborar con el desarrollo profesional del docente mediante la optimización del desempeño y los resultados de la enseñanza. Cabe señalar que este es el propósito fundamental en los sistemas de evaluación interno y 2) obtener información para tomar alguna decisión respecto al docente. La primera lleva a una evaluación formativa y la segunda a una de tipo sumativa.

Entre las múltiples acciones que pueden realizarse para el mejoramiento de la calidad, hay plena coincidencia en que la evaluación docente juega un papel preponderante, ya que permite caracterizar su desempeño y por lo tanto orientar las acciones encaminadas a propiciar su desarrollo futuro. Hay consenso en la idea que el fracaso o éxito de todo sistema educativo, depende en gran medida de la calidad del desempeño de sus docentes.

Durante varias décadas se trabajó en el sector educacional bajo el supuesto de que el impacto de las condiciones socioeconómicas y culturales externas al sistema educativo sobre las posibilidades de éxito de los escolares era tan fuerte, que muy poco podía hacerse al interior de las Escuelas para contrarrestarlas en el caso de que estas fueran negativas. Desde los años cincuenta hasta los ochenta la investigación educativa reforzó este supuesto.

El resultado más consistente de la misma en esos años se refería a la capacidad explicativa del contexto socioeconómico y cultural sobre los logros de la gestión escolar. En el último decenio del siglo pasado los sistemas educativos priorizaron los esfuerzos encaminados al mejoramiento de la calidad de la educación y en ese empeño se identificó al "Desempeño Profesional del Docente" como muy influyente para lograr un salto cualitativo (Schulmeyer, 2002).

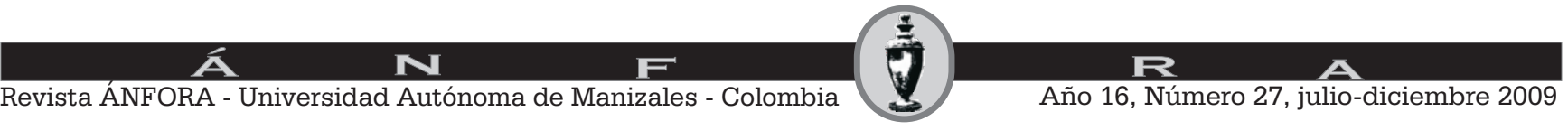


En América latina, muchos agentes educativos consideran que para que se generen necesidades de autoperfeccionamiento continuo de su gestión en el personal docente, resulta imprescindible que éste se someta consciente y periódicamente a un proceso de evaluación de su desempeño. Tanto en América Latina como en los países de Europa del Este, la prioridad es elevar la calidad de la docencia; en estos países hay una fuerte incidencia en establecer escalafones docentes y sistemas de evaluación externa que animen a los educadores a desarrollar mejor su trabajo y a ser recompensados por ello. En cambio, en los países de Europa Occidental, la evaluación se entiende más como un proceso de reflexión personal para el desarrollo profesional, y los sistemas de promoción, como una manera de mantener motivados a los docentes.

La evaluación a los Docentes y el desarrollo de su carrera profesional son considerados temas que tienen incidencia en su desempeño. Muchos países han avanzado en este sentido con la instalación de sistemas de evaluaciones apoyadas en uno o varios modelos teóricos. Aún así, se puede observar que los procesos de implementación muchas veces están cubiertos por el velo del control y sanción.

(UNESCO, 2006)

El sistema de Evaluación de Desempeño Docente necesita ser visto como un medio de apoyo a los docentes, que valora y reconoce su trabajo, su buen desempeño. Un mecanismo que los impulsa a progresar en los años que estén en la docencia. Además, de ser considerado un mecanismo capaz de contribuir a fortalecer su protagonismo y corresponsabilidad en los cambios educativos.

En esta línea es que las actuales preocupaciones de los sistemas educativos de América Latina y Europa buscan desarrollar sistemas de Evaluación de Desempeño Docente que contribuyan al desarrollo profesional de los profesores y con ello al mejoramiento de la calidad de la enseñanza. Más allá de esa común preocupación, las decisiones adoptadas en cada país han sido radicalmente diferentes en su planteamiento y desarrollo, puesto que hay notables diferencias en los diversos sistemas educativos.

Relacionar la evaluación docente con la de la Escuela en su conjunto es realmente una necesidad. El profesor desarrolla su tarea en una organización;

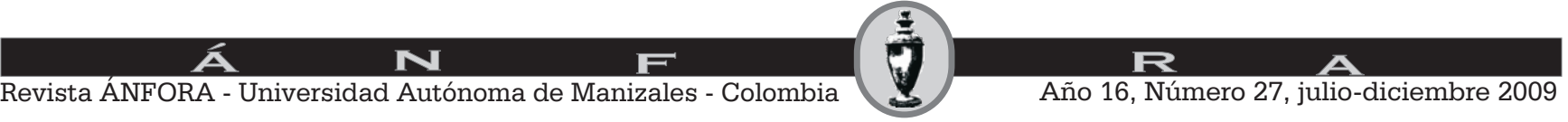


no es posible evaluar al profesor sin tener en cuenta los valores de su entorno laboral, su cultura y su contexto. Por esta misma razón, es necesario incorporar al Docente tanto en el proceso como en los resultados de la evaluación docente. El gran reto del sistema de evaluación de desempeño docente es encontrar la forma de hacer que la evaluación se convierta en una oportunidad de superación profesional. Es más difícil saber como utilizar los resultados con fines de desarrollo profesional, que llevar a cabo la evaluación poniendo puntuaciones o detectando las dificultades y aspectos a ser mejorados. Esto porque la clave está en la finalidad de la evaluación docente, es decir, en el "para qué", en respuesta a ello ciertamente la finalidad básica es la optimización de la calidad de la enseñanza y para ello se ha de centrar en el desarrollo profesional del docente.

En países europeos como Alemania, Eslovenia, Francia, Grecia, Lituania, Malta, Polonia, Portugal, Reino Unido, república Checa entre otros y de América Latina como Argentina, Bolivia, Chile, Colombia, Costa Rica, El Salvador, Honduras, México, Perú, Puerto Rico, Uruguay y otros, se ha regulado algún tipo de evaluación del desempeño docente de carácter externo, las que exigen una gran cantidad de matizaciones para ajustarse a la realidad. Ellos tienen como uno de sus propósitos básicos, explícitamente declarado, el mejoramiento de la calidad de la enseñanza, es decir, buscan colaborar con el desarrollo profesional del docente. Otro de los propósitos en varios países, es que se pretende obtener información con vistas a seleccionar y/o clasificar a los docentes para tomar alguna decisión administrativa, es decir, con repercusiones duras relacionadas con su salario o su promoción, llegando incluso a incidir, en su futuro como docente.

Respecto a las propuestas de evaluación docente se observa una gran variabilidad entre países. Ningún país sigue un marco teórico puro, se apuesta a una visión compleja y múltiple de lo que es un docente de calidad. La Evaluación de Desempeño Docente de los distintos países está sustentada en uno o más modelos acerca de la caracterización del "Buen Docente". Los modelos utilizados se caracterizan por estar centrados sobre rasgos o factores, las habilidades, en las conductas manifestadas en el aula, desarrollo de tareas, en los resultados y en la profesionalización. Utilizando como criterio básico el propósito de la evaluación del desempeño docente es posible identificar cinco modelos diferenciados aún cuando en algunos casos imbriquen elementos de uno u otro:

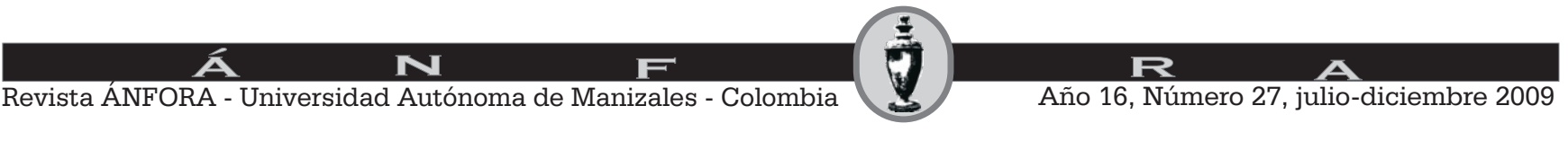


- Evaluación del desempeño docente en conjunto con la evaluación del centro educativo con énfasis en la autoevaluación.

- Evaluación del desempeño docente para casos especiales.

- Evaluación del desempeño como insumo para el desarrollo profesional

- Evaluación como base para un incremento salarial

- Evaluación para la promoción en el escalafón docente

El papel del Estado es fomentar la creación de una cultura evaluadora y aportar modelos y recursos para que cada Centro pueda establecer su propio camino. (UNESCO, 2007)

Chile es distinguido como una excepción respecto a otros países, ya que el sistema de Evaluación Docente explicita los fundamentos teóricos que la sustenta a través del Marco para la Buena Enseñanza. Este Marco es considerado como ecléctico puesto que recoge aspectos de habilidades, conductas en aula, desarrollo de tareas, y actividades relacionadas con la profesionalización. Por ello es considerado un ejemplo de los modelos desarrollados en América Latina.

No existe un modelo único común de lo que se considera un docente de calidad en América Latina. La siguiente tabla muestra los aspectos que se evalúa en los Docentes en Chile, Colombia, Costa Rica, Cuba, California, Perú, Puerto Rico. Pudiéndose observar que las variables más evaluadas son: preparación, clima de aula y motivación, desarrollo de la docencia y cumplimiento de normas, siendo el país que más variables considera en su evaluación Costa Rica. (UNESCO 2006).

A continuación se presenta de manera sintetizada las conclusiones de estudios realizados respecto a la evaluación docente tanto en América latina como en Europa. (Informe Mundial. UNESCO, 2007)

Se ha regulado un sistema de evaluación externo del desempeño en muchos países de Europa del Este y algunos de Europa Occidental y la mayoría de los países de América Latina. Respecto a los propósitos por los cuales se realiza la evaluación docente, se señalan principalmente mejorar o asegurar la calidad de la enseñanza (evaluación formativa) y obtener información para tomar alguna decisión administrativa respecto al docente (incremento salarial, promoción).

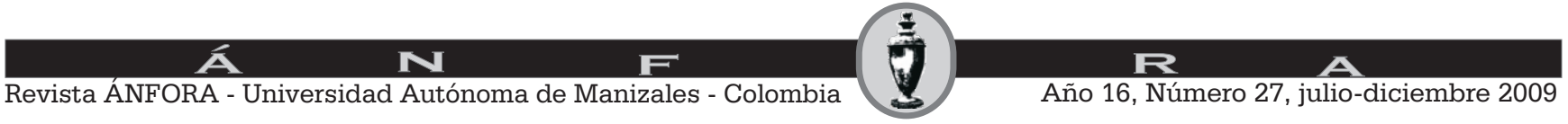


En relación a este último punto, las repercusiones de los sistemas de evaluación externo del desempeño docente se establecen sobre la promoción en el escalafón horizontal (la mayoría de los países de América Latina y bastantes europeos), sobre el salario (tres países de América Latina y cinco países de Europa), como criterio también, para la promoción vertical y ciertas repercusiones negativas.

Respecto a los instrumentos más utilizados se puede desprender del estudio que todos los países utilizan una combinación de instrumentos de obtención de información para evaluar a los docentes y que en ocasiones se reglamentan los instrumentos, mientras que otras veces es cada Escuela o cada autoridad local quien decide. Por otra parte se establece que las repercusiones de la evaluación deben estar ligadas al tipo de instrumento y los utilizados con mayor frecuencia son la observación del aula, entrevista o cuestionario al docente, informe de la dirección del centro, cuestionarios dirigidos a los alumnos y/o a las familias, test y pruebas estandarizadas, Portafolio del Profesor, pruebas de rendimiento a los alumnos y diferentes instrumentos de auto-evaluación.

Finalmente se puede concluir que hay preocupación en América y Europa por desarrollar sistemas de carrera docente y de evaluación del desempeño docente. Sin embargo, las decisiones adoptadas en cada país son muy diferentes que responden a explicaciones tales como la tradición educativa y las necesidades educativas prioritarias.

Respecto a los responsables de este proceso, lo habitual tanto en América Latina como en Europa, es que los principales agentes responsables de la evaluación sean las personas que ocupan los puestos directivos de los centros educativos junto a la supervisión educativa. En otros casos quienes se responsabilizan de este proceso son las autoridades educativas como el caso de México, España e Italia.

\subsection{Evaluación de Desempeño Docente en Chile}

El Ministerio de Educación en un acuerdo tripartito con el Colegio de Profesores y la Asociación Chilena de Municipalidades concordó un Sistema Nacional de Evaluación de Desempeño Profesional Docente, el cual nació el 25 de junio del año 2003. Se orienta a mejorar la labor pedagógica de los docentes de aula del sector municipal.

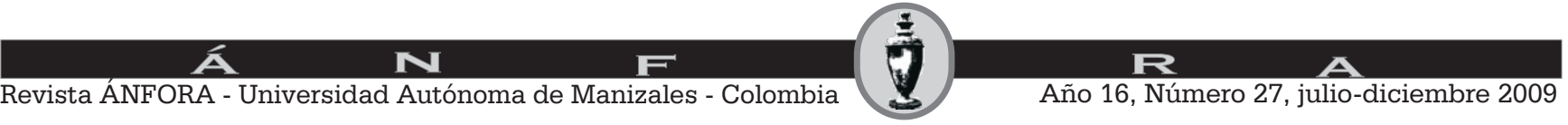


El proceso de evaluación docente es de carácter formativo y se orienta a mejorar el desempeño del profesorado, a promover su desarrollo profesional continuo y por ende al mejoramiento de la calidad de la educación. Se reconoce el carácter explícito de este sistema evaluativo dado que el docente está al tanto de los criterios con los cuales será evaluado, siendo ellos señalados en el Marco para la Buena Enseñanza. Este proceso evalúa a los profesionales de la educación que se desempeñan como docentes de aula en establecimientos del sector municipal y fue puesto en marcha a partir de agosto del 2003.

Está regulado por el artículo 70 del Estatuto Docente, reemplazado por la letra d) del artículo de la ley $\mathrm{N}^{\circ}$ 19.993, publicada en el Diario Oficial el 12 de febrero de 2004. Dicho artículo reemplaza al antiguo sistema de calificaciones y establece el nuevo sistema de evaluación. Se establece que se aplicará a cada docente cada cuatro años, excepto si obtiene un nivel de desempeño final Insatisfactorio, en cuyo caso debe evaluarse nuevamente al año siguiente.

En el mismo proceso de la evaluación Docente y en conformidad a lo dispuesto en la Ley $N^{\circ}$ 19.961, promulgada el 9 de agosto de 2004, se enmarcan los Planes de Superación Profesional, con acciones de carácter formativo diseñadas y ejecutadas por los Municipios. Su propósito es disminuir las brechas de formación de los docentes con desempeño básico e insatisfactorio detectadas en la evaluación docente. La intención que orienta los Planes de Superación Profesional es que a nivel comunal se constituyan espacios locales de desarrollo profesional que permitan a los docentes el aprendizaje y/o actualización de las competencias, conocimientos y habilidades establecidas en el Marco para la Buena Enseñanza y, por esta vía, el mejoramiento de sus prácticas docentes. (Docentemas.cl, 2004).

El fin último de los Planes de Superación Profesional a cargo de los Municipios o Corporaciones municipales responsables tanto del diseño como de la ejecución pedagógica y operativa de las acciones de superación profesional, pretende reducir las brechas de formación detectadas en la Evaluación de Desempeño Profesional Docente a través del perfeccionamiento de los profesores con desempeño Básico e Insatisfactorio. Se busca que los docentes cuenten crecientemente con más y mejores herramientas profesionales, que contribuyan eficazmente a elevar la calidad de los aprendizajes de sus alumnos y alumnas.

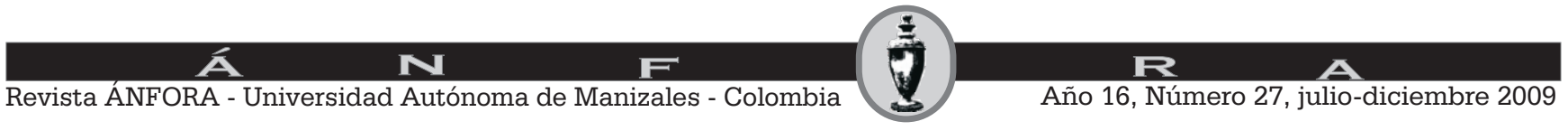




\subsection{Precedentes en Chile sobre Evaluación Docente}

Dentro de la historia de la educación en Chile, existen precedentes acerca de la evaluación docente. Ya en el año 1890 Miguel Antonio Ponce, escribió Prontuario de Legislación Escolar, esto corresponde a una Recopilación de leyes, decretos circulares y resoluciones sobre instrucción primaria. Libro en el cual, ya se evidencian los primeros intentos de algún tipo de evaluación a la función docente. Un reglamento de 1844 le encargaba la dirección de todos los establecimientos de instrucción científica y literaria, como entonces se denominaba a los Liceos, cierto grado de jurisdicción sobre todos los empleados en la instrucción pública, en virtud de lo cual se podía reprender, suspender por algún tiempo o pedir al Gobierno la separación de los empleados considerados ineptos, inmorales o que falten en materia grave a sus deberes. (Revista DOCENCIA, No 23, agosto, 2004).

Continuando con la perspectiva histórica de la educación en Chile, se está de acuerdo en que no sólo ha sufrido diversos cambios de paradigmas, sino que también cambios en la función de quienes intervienen en ellas, pasando de intelectuales a simples técnicos. (Barrios, 2006)

A partir de fines del S. XX, se comienza a implementar la actual reforma educacional, la cual tiene una gran influencia en Evaluación Docente, ya que bajo este contexto se comienza a hacer "uso creciente de la evaluación del sistema, de los establecimientos y de los logros del aprendizaje" (Núñez, 1997)

\subsection{Objetivo de la Evaluación Docente en Chile}

En Chile, como en muchos otros países la evaluación Docente se orienta al mejoramiento de la labor pedagógica para contribuir al aseguramiento del aprendizaje de calidad, y equidad en niños y jóvenes. En otras palabras al Desarrollo y Fortalecimiento de la profesión docente con el fin de favorecer mejoras en el aprendizaje.

A continuación se presenta de manera resumida los aspectos más relevantes que caracterizan la Evaluación Docente en Chile.

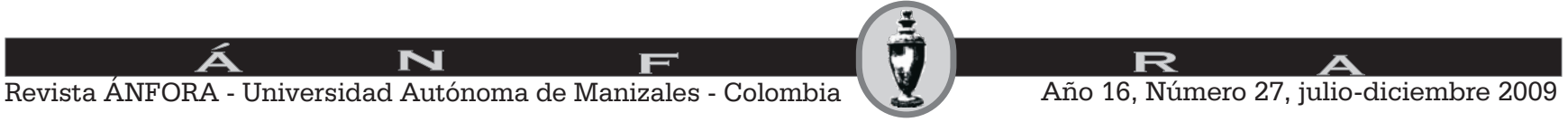




\subsubsection{Principales características de la Evaluación Docente}

- Tiene un carácter formativo, orientada a mejorar la labor pedagógica.

- La evaluación es explícita, el docente conoce los criterios con los cuales será evaluado (Marco para la Buena Enseñanza).

- Se expresa en 4 niveles de desempeño: Destacado, Competente, Básico e Insatisfactorio.

- Se evalúa docentes de aula del sector municipal con al menos un año de ejercicio de la profesión.

- El resultado de la evaluación de cada docente tiene una vigencia de 4 años (excepto insatisfactorios).

- En el Marco para la Buena Enseñanza se establecen los Niveles de desempeño docente, los cuales cumplen con ciertas características que se explicitan a continuación.

\subsubsection{Niveles de Desempeño Docente}

Destacado: Indica un desempeño que clara y consistentemente sobresale con respecto a lo que se espera en el indicador evaluado.

Competente: Indica un desempeño adecuado al indicador evaluado. Aun cuando no excepcional, se trata de un buen desempeño.

Básico: Indica un desempeño que cumple con lo esperado en el indicador evaluado, con cierta irregularidad (ocasionalmente). Se aprecian debilidades, pero su efecto no es severo ni permanente.

Insatisfactorio: Indica un desempeño que presenta claras debilidades en el indicador evaluado y éstas afectan significativamente el quehacer docente.

Cada docente evaluado conoce previamente los criterios con los que será evaluado, contenidos en el Marco de la Buena Enseñanza. Existen además, cuatro instrumentos de evaluación:

a) Diseño e implementación de una Unidad Pedagógica

b) Evaluación final de la Unidad Pedagógica

c) Reflexión sobre su quehacer docente

d) Filmación de una clase

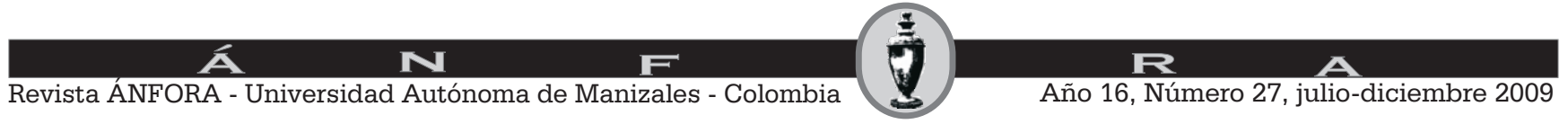


Lo que se traduce en:

- Autoevaluación (Propia perspectiva )

- Informes de Referencia de Tercero (Perspectiva de superior jerárquico)

- Entrevista Evaluador Par (Perspectiva de un colega)

- Portafolio (Evidencia directa)

El Marco para la Buena Enseñanza, señala el conjunto de responsabilidades que un docente debe cumplir en el aula, la escuela y la comunidad que contribuyen significativamente al éxito de un profesor con sus alumnos. En él se establecen cuatro dominios a evaluar:

Dominio A: Preparación para la Enseñanza. Conocimiento de la disciplina que se enseña y competencias pedagógicas y didácticas necesarias para organizar el proceso de enseñanza.

Dominio B: Creación de un ambiente propicio para el aprendizaje. Capacidad del profesor para promover un clima de confianza, aceptación y respeto que favorezca el aprendizaje de todos los estudiantes.

Dominio C: Enseñanza para el aprendizaje de todos los estudiantes. Habilidad para implementar situaciones de aprendizaje que, aprovechando los saberes de los estudiantes, logren que ellos se involucren y se comprometan en su propio proceso de aprendizaje.

Dominio D: Responsabilidades profesionales. Capacidad de reflexionar sobre la propia práctica pedagógica y de establecer relaciones de calidad con los colegas, el establecimiento, las familias de los estudiantes y el sistema educacional en su conjunto.

Los resultados se informan al docente, Director y Jefe DAEM de la siguiente manera:

- Al Docente: Informe descriptivo que señala los resultados en cada instrumento destacando fortalezas y debilidades detectadas.

- Al Director del establecimiento: Informe general con la categoría final de desempeño de cada docente. Además, grafica los resultados al nivel de

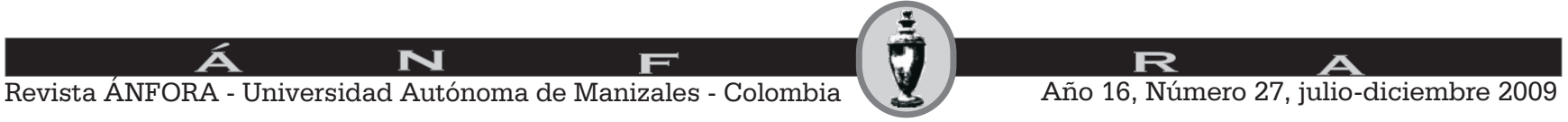


establecimiento, comuna y país.

- Al Jefe DAEM: Informe general con la categoría final de desempeño de cada docente evaluado por establecimiento. Grafica los resultados de cada establecimiento, comuna y país.

\section{4. ¿Después de los resultados?}

El proceso de Evaluación de Desempeño Docente no finaliza con la entrega de resultados, por el contrario es necesario realizar una entrevista con el propósito de comunicar los resultados de la evaluación de manera que el docente pueda tener la posibilidad de mejorar su trabajo a partir de una comunicación clara e inequívoca de su desempeño. Esta instancia le brinda la posibilidad de comprender lo que se espera de él en términos de calidad, cantidad y método de trabajo. Es muy importante que el docente evaluado tenga una idea clara de como está desempeñando su trabajo, resaltando sus puntos fuertes y débiles, y comparándolos con los patrones de desempeño esperados. Muchas veces, el docente cree subjetivamente que todo va bien y puede desarrollar una idea distorsionada respecto a su desempeño ideal. (Valdés, 2000)

La participación del Director y Jefe Técnico del colegio abre la posibilidad que ellos se involucren en todo momento dejando la instancia de discutir las medidas y los planes para desarrollarlos mejor y utilizar las aptitudes del profesor en beneficio de su desarrollo profesional. Lo que se traduce en una comprensión sobre qué necesita entender, cómo podrá mejorar su desempeño y especialmente, participar activamente en la determinación de las medidas para tal mejora. En este contexto se genera un nuevo beneficio a favor de las relaciones personales entre equipo de gestión y docentes, ya que se fortalecen para el logro de un desarrollo de relaciones humanas fuertes y sanas.

Las buenas relaciones humanas en el trabajo requieren de un diálogo franco y cordial de hechos, aciertos, potencialidades y problemas entre los directivos y el docente evaluado. A veces resulta difícil tener habilidad de presentar los hechos y lograr que el docente, al terminar la entrevista, quede convencido de desarrollar y ajustar su desempeño al nivel exigido por sus funciones, y sea consciente de los aspectos positivos y negativos de su desempeño. El éxito de una entrevista de evaluación depende de muchos factores. La entrevista debe ser debidamente preparada, para que la comisión evaluadora sepa de

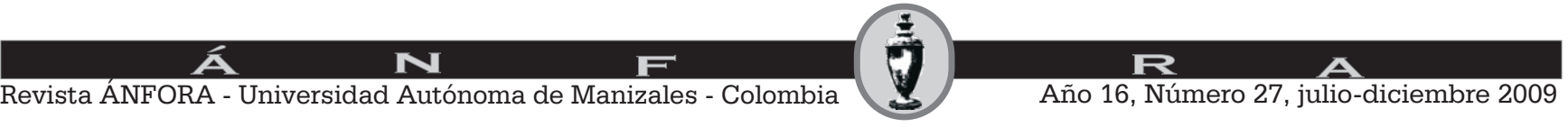


antemano lo que dirá al evaluado y cómo lo dirá y de esta forma asegurar el éxito del objetivo propuesto.

La entrevista entre el evaluador y el evaluado debe constituirse en una oportunidad de crecimiento profesional para ambos. El docente en una actitud de superación deberá reflexionar permanentemente sobre las dificultades que tuvo en el período evaluado, analizar toda la información sobre su desempeño. Además, quien informe los resultados debe evitar conducir la entrevista de evaluación como si fuera una tarea de rutina, puesto que es necesario tener presente que el docente evaluado en nivel Básico o Insatisfactorio se autopercibe como un mal profesor, por lo que su estima profesional podría estar dañada.

Por otra parte, el encargado de informar de los resultados no debe perder de vista que existen algunos docentes que presentan una conducta profesional no adecuada, caracterizada por recelos, preocupaciones y prejuicios, que en ocasiones no son del todo injustificadas, y que requieren de un tratamiento muy profesional y convincente a los efectos de lograr convencer y no vencer al evaluado.

\section{Planes de Superación Profesional}

Los Planes de Superación Profesional buscan reducir las brechas de formación detectadas en la Evaluación del Desempeño Profesional Docente a través del perfeccionamiento de los profesores con desempeño básico e insatisfactorio. Estos Planes de Superación Profesional están normados por el decreto № 192, de 2004, del Ministerio de Educación, que reglamenta la Evaluación Docente.

Los PSP están definidos como un "Conjunto de acciones de formación docente, diseñadas y ejecutadas de conformidad a este reglamento, dirigidas a favorecer la superación de las debilidades profesionales que evidencien los docentes con nivel de desempeño Básico o Insatisfactorio", y en su título IX, De los Planes de Superación Profesional, regula y delimita las responsabilidades de los diversos actores involucrados en el diseño, ejecución y evaluación de estos planes que responden al carácter formativo de la evaluación docente.(MIDE UC, 2007)

La intención que orienta los Planes de Superación Profesional es que a nivel comunal se constituyan espacios locales de desarrollo profesional que

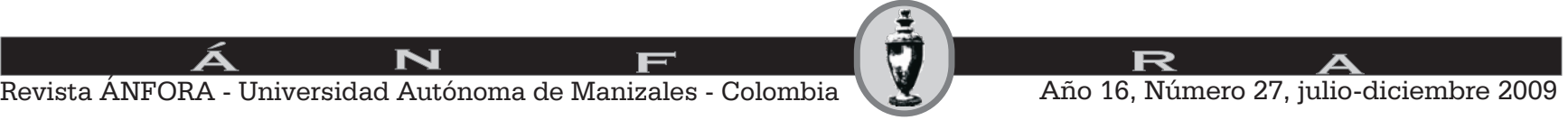


permitan a los profesores el aprendizaje y/o actualización de las competencias, conocimientos y habilidades establecidas en el Marco para la Buena Enseñanza y, por esta vía, el mejoramiento de las prácticas docentes, es decir que los docentes cuenten con más y mejores herramientas profesionales, que contribuyan eficazmente a elevar la calidad de la enseñanza.

Los Planes de Superación Profesional deberán traducirse en una acción de aprendizaje y reaprendizaje respecto de las competencias, conocimientos, habilidades, dominios y criterios establecidos en el Marco para la Buena Enseñanza aprobado por el Ministerio de Educación y a partir de las necesidades de desarrollo profesional derivadas de los informes de resultados de la evaluación de desempeño docente. Sin duda que el logro de este fin dependerá en gran medida del grado de eficiencia de la gestión de cada Plan de Superación Profesional Comunal. Esta gestión es de responsabilidad de los Municipios o Corporaciones, quienes deben diseñar y ejecutar pedagógica y operativamente sus distintas acciones de superación profesional.

Por su parte, a los profesores que hayan obtenido un resultado Básico o Insatisfactorio, les corresponde someterse a las acciones de los Planes de Superación Profesional, que el Municipio o la Corporación Municipal haya planificado para superar las brechas de formación detectadas en la evaluación docente, de manera que puedan mejorar los niveles de desempeño en la siguientes evaluaciones a que deban someterse.

Por su parte, al Ministerio de Educación, a través del Centro de Perfeccionamiento, Experimentación e Investigaciones Pedagógicas (CPEIP), le corresponde aprobar, monitorear y evaluar la aplicación de los PSP, con el fin de asegurar que estas acciones sean pertinentes, oportunas y efectivas. Asimismo, al Ministerio de Educación también le compete el traspaso de los recursos económicos a los municipios y la revisión de las correspondientes rendiciones presupuestarias. El monto de los recursos económicos a transferir se establece anualmente en la Ley de Presupuestos y se distribuye en función del número de docentes evaluados con desempeño Básico e Insatisfactorio, perteneciente a la dotación docente de cada Municipio o Corporación Municipal, al mes de abril de cada año.

Se ha elaborado un Manual de los Planes de Superación Profesional, el cual pretende ser un aporte a la gestión comunal en la materia y está dirigido al

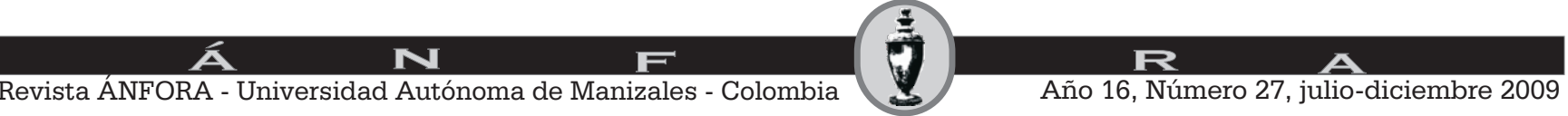


equipo de profesionales responsable del diseño, implementación y rendición de los PSP

Las actividades que pueden contemplar los PSP corresponden a las siguientes posibilidades son: tutorías o asesorías provistas por profesionales idóneos, participación en cursos, participación en talleres o seminarios organizados por entidades académicas o de capacitación, lecturas recomendadas para lo cual se deberá proveer de material bibliográfico u orientaciones para acceder a información disponible en Internet, observaciones de clases llevadas a cabo por docentes destacados u otros profesionales destacados. También se pondrá a disposición de las comunas materiales de apoyo pedagógico para los docentes con nivel de desempeño Insatisfactorio. Este material será de carácter complementario a las actividades de superación profesional de las comunas.

Respecto a las orientaciones contenidas en el decreto $\mathrm{N}^{\circ} 192$ respecto a los PSP, se desprende que:

- Los planes de superación son anuales y las comunas los deben diseñar y llevar a cabo todos los años para los docentes evaluados en el nivel Básico e Insatisfactorio pertenecientes a su comuna.

- Los PSP deben ser presentados por todos los municipios o Corporaciones Municipales que tengan profesores con desempeño de nivel Básico o Insuficiente.

Los Planes de Superación Profesional deben necesariamente contener acciones de superación profesional para todos los docentes con nivel de desempeño Insatisfactorio, las que deberán estar desarrolladas en, a lo menos, un 50\% al inicio de la nueva evaluación anual a que deben someterse. Esto es antes del inicio del segundo semestre del calendario escolar respectivo.

Para el caso de los docentes evaluados en el nivel Básico, las acciones de superación profesional, podrán estar destinadas al conjunto o una parte de estos docentes considerando que el plan de superación es anual y que el derecho de estos Docentes a participar de las acciones de superación puede hacerse efectivo en un plazo mayor, dado que deben evaluarse cada cuatro años.

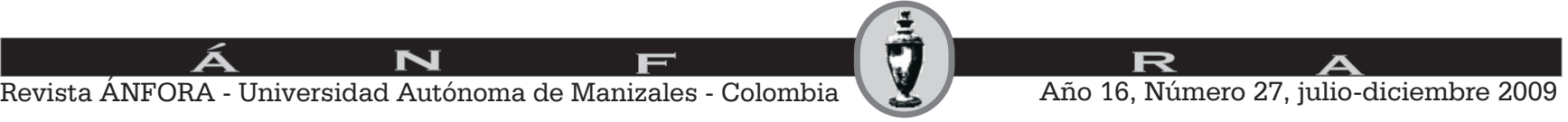


El financiamiento del PSP será transferido a los Municipios o Corporaciones Municipales por el Ministerio de Educación a través del CPEIP, esto en función del número de docentes evaluados en nivel Básico e Insatisfactorio vigentes al mes de abril del año respectivo.

El Ministerio de Educación, a través del CPEIP, cautelará del buen uso pedagógico y monetario de los recursos transferidos para la ejecución de los PSP.

El Municipio o Corporación Municipal deberá rendir según corresponda, los dineros transferidos para la realización del PSP, a más tardar al mes de noviembre de cada año.

Cada Municipio o Corporación Municipal recibe un informe de los resultados de la evaluación de sus docentes, a partir de su análisis los equipos técnicos deberán detectar las áreas críticas del desempeño profesional de sus docente, y con ello elaborar los planes que se implementarán en la comuna para el aprendizaje y la actualización de los conocimientos, habilidades y competencias profesionales que permitan a los Docentes mejorar su trabajo pedagógico. Además, se ha creado un mecanismo mediante el cual cada Municipio o Corporación podrá diseñar, incorporar información atingente al proceso y rendir su Plan. Este consiste en un software, que a nivel de diseño permite consignar información respecto a la identificación de los responsables del diseño e implementación del Plan y aspectos relacionados con los docentes mal evaluados, financiamientos y organismos ejecutores del PSP.

De acuerdo al manual operativo de PSP los antecedentes que es necesario tener a la vista para el diseño de los PSP son:

- Los informes de resultados de los Docentes Evaluados de la comuna.

- La opinión de los Directores de los establecimientos educacionales que han participado del proceso de evaluación docente, quienes conocen directamente a los docentes y reciben un Informe de Resultados de la Evaluación Docente de su Establecimiento.

- El informe que contiene el perfil promedio de las dimensiones del portafolio correspondiente a los docentes mal evaluados de la comuna.

- El Marco para la Buena enseñanza, que constituye la guía básica sobre la

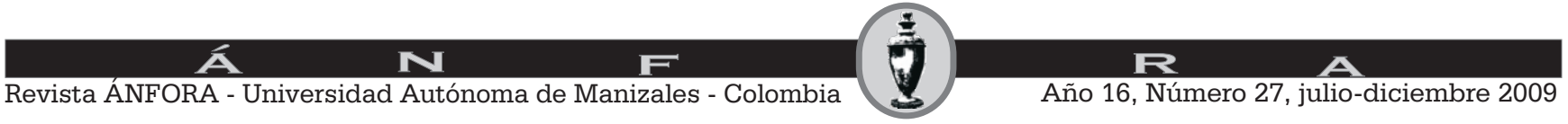


cual se estructura el sistema de evaluación del desempeño profesional docente.

- Aprovechar todos los recursos de capacitación docente, los existentes en la comuna, en la Unidad Educativa, las que se desarrollan en el Área de Formación Continua del CPEIP (Talleres Comunales, Pasantías Nacionales) tomando en cuenta que constituyen importantes recursos complementarios a las acciones de carácter formativo.

3.1. Sistema de Seguimiento, Monitoreo y Evaluación de los Planes de Superación Profesional

Con el fin de asegurar que las acciones de superación profesional cumplan con la condición de ser adecuadas, pertinentes, oportunas y efectivas, el CPEIP administrará directamente un Sistema de Seguimiento, Monitoreo y Evaluación de la ejecución de los PSP. Los objetivos del sistema de seguimiento, monitoreo y evaluación son velar por el logro de los resultados esperados en cada uno de los PSP, para que éstos cumplan con satisfacer las necesidades de formación de los docentes con desempeño Básico e Insatisfactorio de la comuna y sistematizar los aprendizajes sobre las acciones educativas que se realicen en el marco de los PSP.

Para lo cual el CPEIP, a través del Área de Acreditación y Evaluación Docente, ha diseñado un sistema que combina una modalidad On Line y una en terreno. Es destacable que este sistema permite conocer la opinión que tengan los docentes participantes en el PSP tengan respecto a las actividades de formación. La implementación de este sistema permitirá:

- Velar por el logro de los resultados esperados en cada uno de los Planes de Superación Profesional para que estos cumplan con satisfacer las necesidades de formación de los docentes con desempeño básico e insatisfactorio de la comuna.

- Sistematizar los aprendizajes sobre las acciones educativas que se realicen en el marco de los Planes de Superación Profesional.

- Contar con información sobre el desarrollo de los PSP que retroalimente los procesos de formación que se realicen desde el Ministerio.

- Observar en terreno la participación de los Equipos Comunales Ejecutores y los Docentes beneficiarios, tanto en los aspectos pedagógicos como la gestión, con el propósito de retroalimentar el proceso de formación de superación

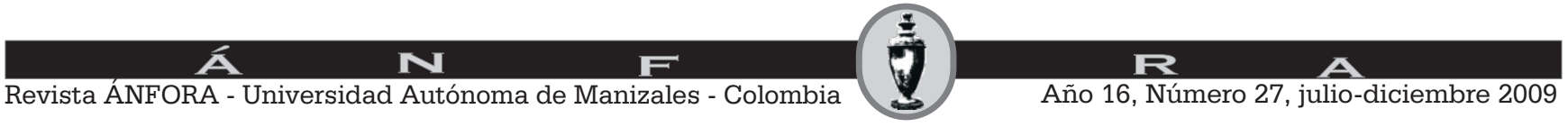


profesional.

- Verificar la realización de las acciones contempladas en los respectivos PSP.

- Fiscalizar la utilización de los recursos de acuerdo al PSP aprobado para cada Municipio. (MIDE UC. cl)

La segunda estrategia de monitoreo mencionada se refiere a la modalidad de supervisión en terreno y tiene como objetivo la constatación del trabajo que se lleva a cabo con los Docentes que se benefician con los PSP comunal. En esta instancia se pretende:

a) Supervisar el cumplimiento de las acciones contempladas en el Plan de Superación Profesional del año, que incluye:

- Constatar la realización de las actividades, plazos y responsables según lo registrado en el Formulario del Plan de Superación Profesional de cada Municipio.

- Velar por la correspondencia entre el uso de los recursos traspasados y los objetivos y resultados educativos del Plan de Superación Profesional.

- Entregar un informe al CPEIP respecto del estado de avance y pertinencia del Plan de Superación Profesional implementado por la comuna monitoreada.

b) Acompañar a los equipos del Municipio en el proceso de gestión de su Plan de Superación Profesional, lo que implica:

- Brindar apoyo técnico en los aspectos organizacionales y relativos a la gestión del Plan de Superación Profesional, cuando sea necesario y se den las condiciones para aquello.

c) Estimular el proceso de reflexión pedagógica y análisis permanente acerca de la evaluación y logros del Plan de Superación Profesional, que incluye:

- Generar al interior del Equipo Municipal instancias de reflexión pedagógica y análisis de los resultados educativos.

- Registrar y sistematizar las intervenciones del seguimiento y monitoreo para retroalimentar al equipo municipal, ejecutores y docentes beneficiarios respecto de la pertinencia del Plan de Superación Profesional implementado.

- Estimular las actividades de coordinación e intercambio entre los Municipios (Redes de Aprendizaje).

- Evaluar cualitativamente el estado de avance y pertinencia del Plan de Superación Profesional implementado.

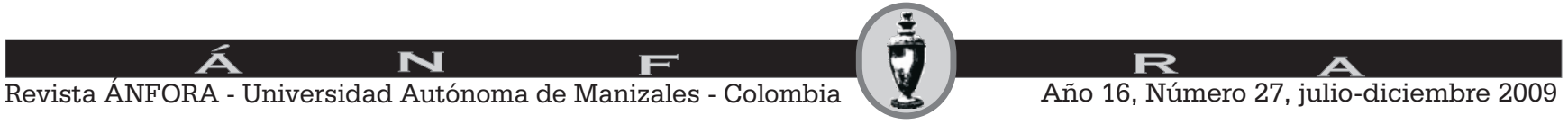


Posterior al diseño de los PSP 2006, el CPEIP encargó al Centro de medición de la Escuela de Psicología de la Universidad Católica de Chile (MIDE UC) para que elaborara un sistema de monitoreo de los PSP en comunas sobre las cuales se tuviera algún indicio de buenas prácticas de diseño e implementación de actividades que respondieran a las necesidades de formación de los docentes, teniendo en consideración el diseño del plan 2006 remitido al CPEIP, llevó a cabo un monitoreo focalizado consistente en un seguimiento y evaluación en terreno de la ejecución de los PSP en una muestra de 17 comunas de nuestro país. Durante el año 2008 se ha llevó a cabo un segundo monitoreo a 50 comunas del país, informe que aún no esta disponible.

\subsubsection{Monitoreo Focalizado de los Programas de Superación Profesional (PSP} 2006)

MIDE UC, consideró este monitoreo como un primer esfuerzo para registrar prácticas interesantes que puedan ser difundidas entre las distintas comunas a modo de efecto de demostración. En ello se detecta algunas características de operación de los PSP y las opiniones de los distintos actores involucrados en este proceso, tales como docentes, ejecutores y encargados comunales.

\subsubsection{Antecedentes relevantes del monitoreo}

La selección de la muestra fue de tipo intencional, estratificada de acuerdo a una reagrupación de los criterios utilizados por la Subdirección de Desarrollo Regional del Ministerio del Interior para construir una tipología comunalmunicipal. Se hizo una agrupación en tres categorías de comunas, considerando las variables dependencia de la comuna del Fondo Común Municipal (indicador mediato del nivel de pobreza de la comuna) y la ruralidad de la comuna.

Las 17 comunas que componen la muestra final son el producto de una selección de un $5 \%$ de las comunas de cada categoría. Se realizaron 65 entrevistas a profesores, 22 a Ejecutores y 17 a Encargados comunales. El total de entrevistas realizadas fueron 104.

Se diseñaron tres instrumentos para detectar las características del proceso de diseño e implementación de los PSP. Estas correspondieron a una entrevista

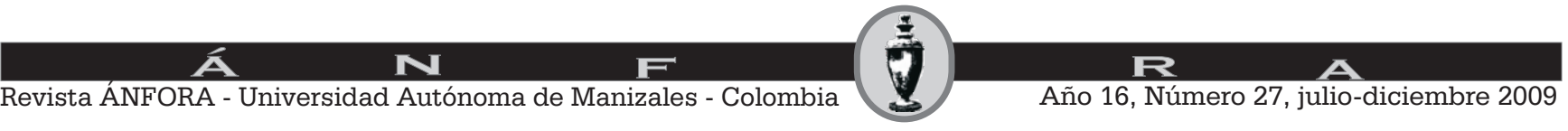


compuesta de preguntas abiertas y cerradas a cada Encargado Comunal, Ejecutores y Profesores. Las entrevistas contemplaban para el caso de los Encargados Comunales y ejecutores áreas de antecedentes personales y académicos, antecedentes laborales, diseño del Programa de Superación Profesional, ejecución y evaluación del mismo. Para el caso de los docentes se incluyó sólo los antecedentes personales y académicos, su participación en las actividades de PSP y evaluación de ellos.

En cada una de las comunas seleccionadas se aplicó una entrevista a los tres actores fundamentales en el proceso de diseño, implementación de los PSP, es decir, se entrevistó a Encargados Comunales, Ejecutores y Docentes evaluados en 2005-2006 en nivel Básico e Insatisfactorio y que eran participantes en los PSP. En cada comuna se seleccionó aproximadamente el $20 \%$ del total de profesores con resultados Básico o Insatisfactorio.

El levantamiento de datos estuvo a cargo de psicólogos de la Universidad Católica, capacitados para este proyecto.

Una dificultad detectada por los entrevistadores, en particular en los cuestionarios de los docentes fue que en una proporción importante de los profesores, el PSP no tuvo actividades específicas que fueran claramente reconocibles. Esto supuso un patrón de respuestas forzadas al formato de la entrevista, o una entrega de información repetitiva que se hacía no por las tendencias reales percibidas, sino que por la necesidad de responder ante una pregunta. Se señala que al no reconocer los sujetos como núcleo del PSP las actividades realizadas, fue imposible contrastar distintas percepciones, opiniones y actitudes por lo que se hizo imposible construir un relato fidedigno de lo que había acaecido en la comuna. Por lo que se concluyó que la unidad de análisis "actividad" no resulta funcional a la detección de prácticas relevantes de los PSP.

Esto indica según mencionan quienes realizaron este monitoreo focalizado, que la técnica de indagación elegida (cuestionario semiestructurado) no fue la más adecuada para lograr el propósito buscado. Esto les sugiere que el próximo monitoreo focalizado en que se persigue detectar actividades y comportamientos específicos debe hacerse con una muestra reducida y con metodología de corte cualitativa aplicando entrevista en profundidad.

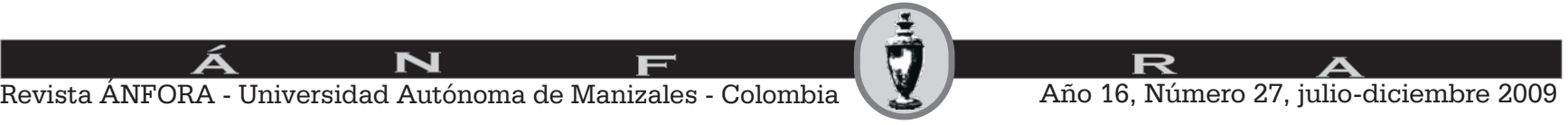


Los resultados de dicho monitoreo se presentan de manera resumida, habiéndose concluido que se encontraron algunas dificultades, las cuales fueron señaladas por los encargados comunales y los ejecutores de los cursos de capacitación de los PSP:

Encargados Comunales señalan:

- Tener poca información sobre entidades ejecutoras, mecánica institucional de los PSP y resultados individuales de la evaluación docente.

- Poseer dificultades al comunicar a los docentes que deben participar en los PSP.

- La necesidad de un instrumento tipo o indicadores de calidad que les permitiera evaluar los resultados de las capacitaciones realizadas.

- La necesidad de contar con resultados individuales y detallados de la Evaluación Docente de los Profesores de manera que la información de los resultados fuese más exacta para la elaboración de un diseño más contextualizado.

Un aspecto de gran relevancia es que un EC mencionara la necesidad que Directores y Jefes Técnicos se hubiesen involucrado más en el diseño del PSP con el fin de realizar un Plan más cercano a la realidad de los Docentes, y no sólo basado en la evaluación que habían obtenido. Otra dificultad que los EC debieron ir resolviendo en el camino fue la falta de experiencia en la elaboración de este tipo de planes. La insuficiencia de recursos económicos, falta de recursos bibliográficos y materiales para los docentes, carencia de equipos audiovisuales de apoyo para implementar adecuadamente las actividades. En este mismo escenario la coordinación de los horarios de las capacitaciones con los profesores participantes fue un problema para la implementación de los PSP, como así mismo la lejanía del lugar donde se llevó a cabo la capacitación. Encontrar ejecutores también fue una dificultad que debieron enfrentar los EC, la carga de trabajo que tampoco les permitía cumplir con los plazos de entrega de los PSP. Otros mencionaron verse afectados por la falta de capacitación e involucramiento del DAEM en los PSP. Por último cabe anotar que otras dificultades señaladas por los EC fue el hecho de planificar el PSP, la falta de una persona que monitoree la implementación de los planes, la falta de información respecto de los PSP, el no involucramiento de los docentes en el diseño y que la participación no fuera obligatoria para los docentes que habían obtenido un nivel de desempeño básico en la evaluación docente.

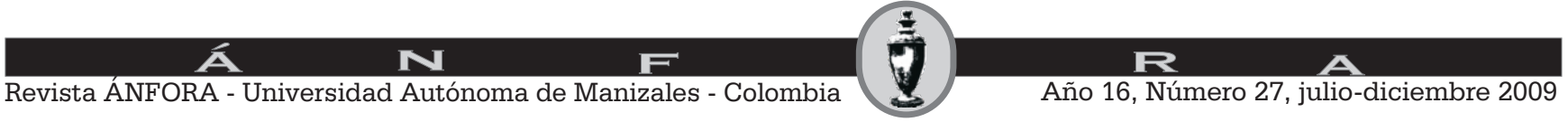


Ejecutores de Cursos de Capacitación dan a conocer que:

- No tienen claridad respecto a objetivos ni al marco en que se inserta PSP

- Un tercio no conocía el diseño del PSP realizado por el Encargado Comunal

- La mitad menciona como principal dificultad la reacción negativa de los docentes hacia los PSP y evaluación docente.

- En general los ejecutores hacen una muy buena evaluación de los PSP como una instancia de actualización de los docentes mal evaluados, lo que podría generar cambios en las prácticas pedagógicas.

- No existe un seguimiento cercano de las actividades que llevan a cabo los ejecutores, ni mecanismos formales que apoyen este seguimiento.

- No se realiza una planificación estratégica (a mediano plazo) de los PSP ni existe conocimiento de que esto se pueda hacer.

- La evaluación aplicada por los ejecutores son poco frecuentes y en los casos que se realizan son laxas.

- Sin embargo, los Encargados Comunales evalúan positivamente a los ejecutores contratados (13 de 16 Encargados volverían a contratarlos)

Respecto a los profesores, ellos reconocen que es difícil haber sido evaluados como Básicos o Insatisfactorios y que la disposición que tienen en relación a los PSP es más bien de distancia y rechazo. Es por ello que la comunicación de esta información a los Docentes debe ser tratado con especial cuidado por los entes responsables, ya que es a través de este primer contacto que los profesores perciben que son tratados según el rótulo de malos profesores o que realmente se abre a una oportunidad de mejoramiento y actualización que pueden aprovechar. Es esta primera actitud con la que luego enfrentan el PSP.

A pesar de la situación descrita, los Docentes hacen una positiva evaluación de los PSP, puesto que valoran las actividades en las que participaron, un 70\% considera que estuvieron relacionadas con su ejercicio profesional y un $83 \%$ rescata su utilidad. Con el mismo optimismo evalúan a los ejecutores de las actividades, otorgando sobre el $90 \%$ de aprobación en nivel de conocimiento, apertura y habilidades pedagógicas, como también 57 de los 62 entrevistados volvería a participar en actividades.

No obstante el informe de monitoreo focalizado señala que más de un $40 \%$ de los profesores entrevistados indica que las capacitaciones adolecen de

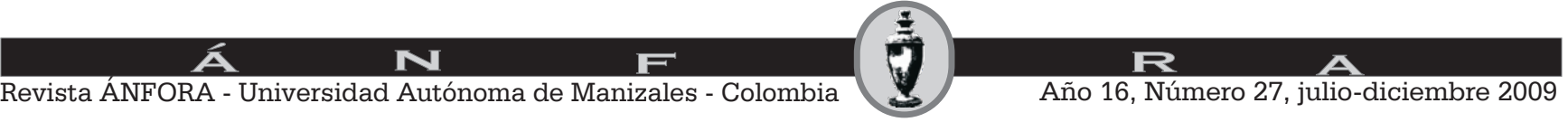


profundidad, mostrándose críticos también, con la corta extensión de los cursos. Finalmente, un tercio señala que no se evaluaron las actividades es las que participaron.

El mismo informe plantea desafíos para una capacitación docente en el ámbito local a partir de que los resultados de la Evaluación Docente muestran heterogeneidad local en las deficiencias identificadas en el desempeño docente, por su parte, los PSP buscan responder contextualizadamente, en el nivel local, a los diferentes tipos de desafíos que presenta dicha evaluación, entonces, el desafío es la instalación y fortalecimiento de espacios locales de desarrollo profesional que permitan a los docentes el aprendizaje y/o actualización de sus competencias, conocimientos y habilidades.

Planteado de otra forma los desafíos que se plantean a partir de este monitoreo son:

- Asumir la heterogeneidad local en los procesos asociados a los PSP

- Imaginar modelos que den cuenta de la heterogeneidad anotada

- Fortalecer una cultura de evaluación (procesos y productos)

- Idear formas o mecánicas que potencien el espacio del PSP (anillos municipal local-regional)

Como fue dicho al inicio de presente artículo el Proyecto Fondecyt "Gestión del conocimiento y reforma del pensamiento en educación. Reformulaciones epistemológicas y sociopolíticas para programas de formación de profesores" apunta a mejorar la calidad de los docentes en ejercicio y para ello es imprescindible conocer la realidad de la evaluación docente en Chile y a partir de ahí realizar aportes sustantivos al mejoramiento del quehacer docente.

\section{BIBLIOGRAFÍA}

Alarcón N., Méndez, R. (2002). Calidad y Productividad en la Docencia de la Educación Superior. Recuperado 10/10/2007 de www. Monografías.com

Álvarez, I. y Topete C. (1996). Estrategia integral de gestión para la calidad de la educación básica, en el siglo XXI. Perspectiva de la Educación desde América Latina vol $2, \mathrm{~N}^{\circ} .3$ y 4 . mayo-agosto.

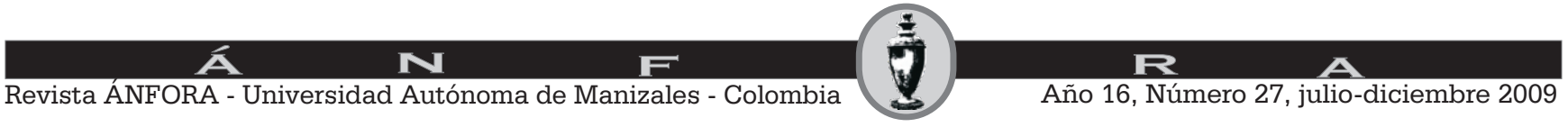


Álvarez,I. y Topete, C. (1997) "Modelo para una evaluación integral de las políticas sobre gestión de calidad en la educación superior". Revista Gestión y Estrategia $\mathrm{N}^{\circ}$. 11-12. Enero-Diciembre, UAM.

Apablaza y otros. (2007). Evaluación Docente. Los cambios que se requieren Informe $\mathrm{N}^{\circ}$ 9. Centro de políticas Públicas. Universidad del Desarrollo.

Barrios P. (2006) Investigación Documental. Instituto de investigación y Desarrollo Educacional. ¿Qué refleja el actual sistema de Evaluación Docente, como política educativa, de la democracia chilena?

Barthes, R. (1972) La Semiología. Editorial Tiempo Contemporáneo. Buenos Aires.

Berger, P y Luckman T (1967). The social construction of reality: A Treatise in the sociology of knowledge. Doubleday, New York.

Bellei, C. (2007). Evaluación docente y mejoramiento del aprendizaje de los alumnos. En seminario Evaluación docente en Chile. Fundamentos, experiencias y Resultados.. MIDE UC octubre 2007.

Borrell, N. (1992). Formación de directores para el cambio institucional. Ponencia II congreso interuniversitario de organización escolar. Sevilla.

Bogdan, R. Taylor, S.J (1987). Introducción a los métodos cualitativos de investigación. Paidós. Buenos Aires.

Canales, M. (2006). Metodologías de investigación social. LOM ediciones. Santiago, Chile.

Casassus, J. (2002). Problemas de la gestión Educativa en América Latina y el Caribe. Recuperado el 10/10/2007, de www.modle.eclac.cl

Colegio de Profesores de Chile AG. Revista Docencia, N²3, Agosto ,2004.pág. 68

Cantú, D. (2001) Calidad educativa y mejora continua. Recuperado 5/10/2007 de www.monografías .com 
Eyzaguirre, B y Le Foulon, C. (2001) La calidad de la Educación Chilena en cifras Estudios Públicos, primavera $n^{\circ} 84$.

Fernández, J. (1999) Manual de Política y legislación educativa. Síntesis cap I. Política educativa y social . pp 11-27 Madrid

Fajardo, M. (1999). Reformas Educativas en América Latina. Balance de una década. PREAL.

Flick, U. (2004). Introducción a la investigación cualitativa. Ed Morata. Madrid.

García, L y otros. (1996) Los retos del cambio educativo. Editorial Pueblo y Educación. pág. 14.

Guerra, M.(2007) Gestión educativa: Teoría política y práctica. I Simposium Internacional de didáctica universitaria.

Hernández Sampieri, R y otros. (1998) Metodología de la investigación . Ed. Mc Graw Hill. México.

Hurtado, J. (2004) Cómo formular objetivos de investigación. Cooperativa Editorial Magisterio. Bogotá.

Imbernón, F. (1996).La formación del profesorado. Formar para innovar. Ed. Magisterio del Rio de la Plata. Buenos Aires.

Kemmis, S (1983). Action Research. Pergamon. London.

Lincoln y Guba. (1985). Naturalistic Inquirí. Sage. Beverly Hills, EEUU

Latorre, A. (1996). Bases metodológicas de la investigación educativa $1^{\circ}$ edición. Editor J. Hurtado. Barcelona.

Manzi, J. (2006) La evaluación del desempeño profesional en Chile. Centro de Medición EPUC. PUC. Santiago.

Maykut, P y Morehouse,R. (1999) Investigación cualitativa. Una guía práctica y filosofica. Ed. Hutado. Barcelona.

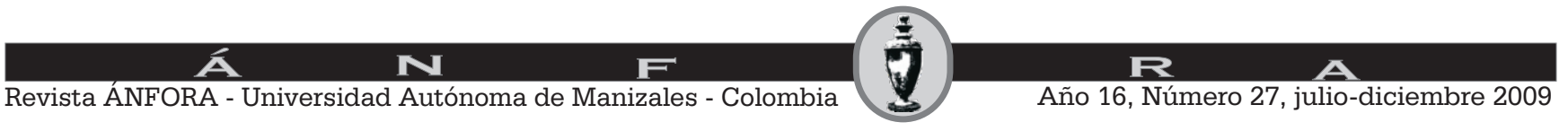


McMillan, J. y Schumacher, S. (2005) Investigación educativa. Ed. Pearson Educación. Madrid.

Mella, O. (1998) Naturaleza y orientaciones teórico - metodológicas de la investigación cualitativa.

Meyer, K. y French, J. (1994) Administración de recursos humanos Brasil.

MINEDUC (2005). Marco para la Buena Dirección. Criterios para el desarrollo profesional y evaluación de desempeño. Publicación de la unidad de Gestión y mejoramiento educativo. Division Educación General. Ministerio de educación . Chile.

Montero, M. (1993). Permanencia y cambio de paradigmas en la construcción del conocimiento científico. Interacción social 3.

Morgan, D.(1988). Focus Group as Qualitative Research. Newbury Park, CA. Sage.

Murillo, F.J. (2007). Evaluación del desempeño y carrera profesional docente. Una panorámica de América y Europa. Santiago de Chile: UNESCO.

Nuñez I, (1997). Las Políticas públicas en Educación. Una mirada histórica 1925-1999). Serie estudios Nº 11 Universidad de Talca IIDE, Talca

OCDE. (2004) Informe Revisión Políticas Nacionales de Educación Chile-2004. Organización para la cooperación y el Desarrollo Económico.

Pérez S, G. (1998). Investigación cualitativa. Retos e interrogantes I. Métodos. Ed. La Muralla. S.A Madrid

Pérez S, G. (1998). Investigación cualitativa. Retos e interrogantes II. Técnicas y análisis de datos. Ed. La Muralla. S.A Madrid.

PREAL. (2003) Reformas curriculares: Las experiencias de los 90 en Perú, Argentina, Chile y Colombia. Rendición de cuentas en educación №3 PREAL, Santiago.

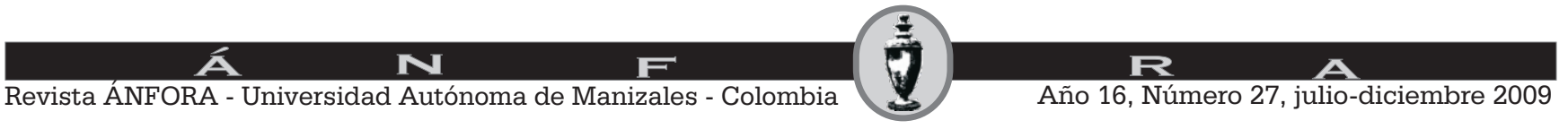


Rodríguez Gómez (1999) Metodología de la investigación cualitativa $2^{\mathrm{a}}$ Edición Ed. Aljibe. Málaga.

Sautu, R. y otros. (2005) .Manual de metodología. Construcción del marco teórico, formulacion de objetivos y elección de la metodología. Clacso libros. Buenos Aires.

Sandoval, M. (2002) Jóvenes del Siglo XXI: sujetos y actores en una sociedad de cambio. Cap. 5 y 7. Ed UCSH. Santiago.

Sandín, M. (2003). Investigación cualitativa. Fundamentos y tradiciones. Ed. McGraw- Hill. Madrid.

Seibold (2000) Calidad educativa y mejora continua. Rescatado el 15 octubre de 2007 de www. Monografías.com

Stake, R. (1998) Investigación con estudio de casos. Ed. Morata. Madrid.

Stufflebeam,D. Shinkfield,A. (1987). Evaluación sistemática. Ed. Paidós Iberica. Madrid.

Schulmeyer, A. (2002).Estado actual de la evaluación docente en trece países de América Latina. Rescatado 20/8/2007 de www.Monografias.com

Schulmeyer, A. (2002) El Desempeño de los Maestros en América Latina y el Caribe: Nuevas Prioridades. Brasilia, Brasil,.

Schulmeyer, A. (2002) Programa de promoción de la reforma Educativa en América Latina. PREAL.

Stake, R. (1998) Investigación con estudio de casos. Ed. Morata. Madrid.

Taylor, S.J. y Bogdan,R. (1987) Introduccion a los métodos cualitativos de investigación. Ed. Paidós Iberica. Barcelona.

Tejada, J. (1998). Los agentes de la innovación en los centros educativos(profesores, directivos y asesores. Ed. Aljibes, S.L. Málaga.

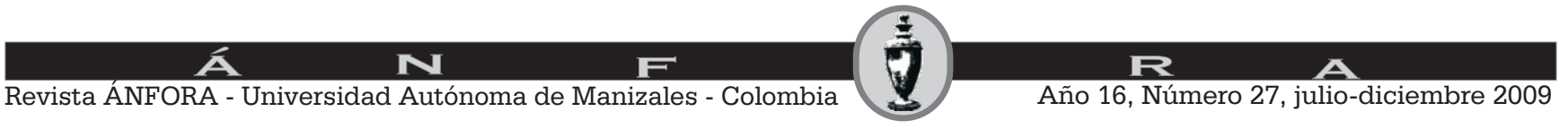


Tenti, E. (2002). Los docentes y la evaluación. Documento presentado en el Seminario Internacional La dimensión política de la evaluación e la calidad educativa en América Latina. Santiago de Chile: MINEDUC-IIPE/UNESCO.

Toranzos, L. (1997) "Evaluación de la Calidad de la Educación". Revista Iberoamericana de Educación $\mathrm{N}^{\circ} 10$

UNESCO. (1990) Declaración mundial sobre la educación para todos Marco de acción. Jomtien, Tailandia.

UNESCO/OREALC. (2002) Formación docente: un aporte a la discusión . La experiencia de algunos países. Santiago, Chile.

Vaillant, D. (2005). Formación de docentes en América Latina. Re-inventando el modelo tradicional. Ed. Octaedro. Barcelona.

Vaillant, D. y Rossel, C. (2004). Construcción de la Profesión docente en América Latina. Tendencias, temas y debates. GTD-PREAL.

Valdés, H. (2000). Evaluación del desempeño docente. Encuentro Iberoamericano sobre evaluación del desempeño docente. Ciudad de México, 23 al 25 de mayo.

Vegas,E. y Umansky,I. (2005) Mejorar la enseñanza y el aprendizaje por medio de incentivos: ¿qué lecciones nos entregan las reformas educativas de América latina? Banco mundial. 